\title{
GE Big Boys Appliances: Towards a Multimodal Discourse Analysis of the SNL Fake Commercial
}

\author{
Karina Clemente-Escobar \\ University of Guanajuato, MEXICO \\ Division of Social Sciences and Humanities
}

Received: 12 June 2021 - Accepted: 30 July 2021 - Published Online: 12 August 2021

\begin{abstract}
Nowadays, comedy shows like Saturday Night Live (SNL) have become popular and entertain many people around the world. For this study, a fake commercial for GE Big Boys Appliances, aired on YouTube in 2018 is analyzed to explore how discourse is used to represent gender roles and stereotypes. To conduct this multimodal discourse analysis, some elements of Systemic Functional Linguistics (SFL) proposed by Halliday (1978), some notions of critical discourse analysis, and some features of the Machin's (2010) visual semiotic framework are employed. The findings portray that the sketch shows a change concerning gender roles through time, but it still promotes the transmission of some classical gender stereotypes. Therefore, it is valuable to study comedy sketches to understand how traditional gender roles and stereotypes are still transmitted in social media.
\end{abstract}

Keywords: multimodal discourse analysis, gender, stereotypes, transmission of gender roles.

\section{Introduction}

Considering the significance of humor in the United States (US) to portrait cultural, political, and social issues and the popularity of the show SNL, this paper aims to analyze the fake commercial for GE Big Boys Appliances available on YouTube since 2018. This sketch illustrates in what manner gender roles have changed through time and explains how housework is a men's job in a humorous and radical way. Contemplating that this video has more than five million visits on YouTube and that gender roles are strongly influenced by media, it is pertinent to evaluate this sketch and identify the ideas behind the discourse presented regarding gender roles and stereotypes. Additionally, this paper provides meaningful information to evaluate how classical gender stereotypes are still transmitted by mass and social media. This paper is presented as follows: first, a literature review to explore concepts related to American humor, a summary of the SNL show, and key definitions of gender roles and stereotypes in the US are delivered. Then, an overview of the methodology adopted is addressed. Finally, the main findings are discussed followed by a general conclusion of the results.

\section{Literature review}

Some researchers have recognized the significance of exploring gender theory including gender roles and stereotypes. In fact, most of the studies on gender, gender power

(C) Authors. Terms and conditions of Creative Commons Attribution 4.0 International (CC BY 4.0) apply. Correspondence: Karina Clemente-Escobar, University of Guanajuato, Division of Social Sciences and Humanities, Guanajuato, MEXICO. E-mail: teacher.kjce@gmail.com. 
K. Clemente-Escobar - GE Big Boys Appliances: Towards a Multimodal Discourse...

relations and stereotypes have determined the importance of exploring gender inequalities and the influence of mass media in shaping individual's views regarding gender issues (Eagly et al. 2012; Gauntlett, 2008). Hence, in this section, fundamental topics and definitions of gender, gender roles, and stereotypes are provided to facilitate the understanding of this paper.

- This sketch emphasizes that men need to be strong and tall to take care of the household chores.

- Traditional gender stereotypes are still transmitted in comedy sketches in the United States.

- The fake commercial promotes the evolution of gender roles, but classical stereotypes are still transmitted.

\subsection{American humor: The Saturday Night Live Show}

Humor is a universal and common in our everyday lives. Martin (2007) defines it as a verbal or nonverbal behavior that could be entertaining, cheerful, and produce laughter. Some authors claim that humor can help people to reduce tension, overcome difficult times, and enhance positive relationships and emotional well-being (Britvec, 2020; Meyer, 2000). However, humor could be different in diverse contexts, situations, and nations.

American humor has become relevant in the last decades as a means to approach and overcome difficult political and social matters (Inge, 2005). For that reason, humoristic pieces have sought presence in literature, cartoons, magazines, animations, radio, films, and TV shows. Sketch comedy TV shows have gained popularity in the US since the 1970's (History website, 2020). Subsequently, comedy has been used to discuss social and political events in a humorous way. Humor usually depends on individuals' contexts, maturity, and level of education. In the case of the SNL show, it has become popular and widely accepted by American adults between 18 and 49 years old and people worldwide.

According to the History website (2020), SNL is an American comedy show created by Lorne Michaels for the NBC channel in 1975. This American comedy show is aired every Saturday from New York and each episode is hosted by a celebrity who delivers an opening and performs sketches to parody contemporary social and political events (Ramos, 2021). These comedy sketches present situations that have a high impact in the American society. It has survived in the media environment for decades by offering spectators creative episodes with a variety of cultural discourses (Marx et al. 2013). As a result, the popularity of the show has risen through the years and it has become an icon of the American culture. Regarding this, Ramos (2021) reported that this iconic sketch comedy show ranked as the number 1 among all comedies in broadcast TV and cable in 2021, despite the Covid-19 pandemic. This show has served as an ideal site to explore issues related to critical race, gender, and political science studies. For this paper, I will analyze the video GE Big Boys appliances aired by SNL in 2018 and now available on YouTube.

\subsection{Gender theory}

Considering social organization, systems of knowledge and beliefs, language and language use, education, etc. (Juschka, 2017). Thus, gender has been a crucial topic of research in different areas of knowledge including the study of gender and language (Bucholtz, 2003). As a matter of fact, there is a debate regarding the biological and social construct of the term (Changxue, 2008). According to this author, the biology construct suggests that gender is stable, natural, and determined by the biological sex male or female. On the other hand, the social construct supports those individuals are not born with behaviors and features of being masculine nor feminine. In fact, they highlight that gender identity develops with exposure to culture, and 
socialization (Changxue, 2008). The biological perspective perceives gender as being fixed. According to this, men and women are born with specific features and they must fulfill specific roles in society. Considering this, Veenstra (2011) argues that inequalities are promoted by combining factors of discrimination such as ethnicity, socioeconomic status, disability, age, gender identity and sexual orientation, among others. Therefore, in the following subsections, some relevant characteristics and recent perspectives concerning gender roles and stereotypes are addressed.

\subsubsection{Gender roles}

A gender role is related to the way in which a man or a woman should behave, speak, or dress so the rest of society could consider their performance as appropriate or acceptable. According to Eagly and Wood (2012) and Rudman et al. (2012), there are some of feminine and masculine roles that distinguish women and men in industrialized economies. Table 1 summarizes these roles.

Table 1. Roles of men and women

\begin{tabular}{|c|c|}
\hline Masculine roles & Feminine roles \\
\hline $\begin{array}{c}\text { Males are family providers (breadwinners) and } \\
\text { full-time workers. }\end{array}$ & $\begin{array}{c}\text { Females are primary caretakers of children and } \\
\text { in charge of nursing infants. }\end{array}$ \\
\hline $\begin{array}{c}\text { Men do the hard work in the house such as } \\
\text { repairing the car and fixing the equipment and } \\
\text { appliances that stop working }\end{array}$ & $\begin{array}{c}\text { Women should do domestic chores such as } \\
\text { cleaning and organizing the house, cooking, } \\
\text { doing the laundry. }\end{array}$ \\
\hline $\begin{array}{c}\text { Men usually become doctors, engineers, } \\
\text { mechanics, pilots or join the army. }\end{array}$ & $\begin{array}{c}\text { Women tend to work as secretaries, teachers, } \\
\text { and nurses. }\end{array}$ \\
\hline
\end{tabular}

Note: Summarized from: Eagly and Wood (2012) and Rudman et al. (2012).

Table 1 provides information about the different roles men and women are expected to fulfill in Western nations. However, women's roles have been shifting radically. According to the US Bureau of Labor Statistics (2009) women represent $47 \%$ of the US labor market and 59\% of American women work outside the home. Therefore, it is more accepted for women to have careers as directors, engineers, scientists, and other fields in which they were not accepted before. Despite this, it is interesting to evaluate how these gender roles are represented in mass media and how they impact gender stereotypes.

\subsubsection{Gender stereotypes}

Mayer and Bell (1975) define a stereotype as the general picture that individuals have in mind concerning hypothetical features that males or females should have rather than how they actually are or the roles they are able to fulfill in society. As a result, stereotypes depend on cultural characteristics and particular expectations of communities.

Gender stereotypes are constantly evolving, and the diverse ways individuals socialize are affecting people's behavior and communication styles. However, the maintenance of stereotypes is complex, and they may decay with time (Le Page \& Tabouret-Keller, 1985). In this order of ideas, there are some masculine and feminine features that could influence the process of stereotyping men and women. Some of these traits are presented in Table 2. 
K. Clemente-Escobar - GE Big Boys Appliances: Towards a Multimodal Discourse...

Table 2. Masculine and feminine characteristics

\begin{tabular}{|c|c|}
\hline Masculine features & Feminine features \\
\hline Physically strong and athletic & Physically weak \\
\hline Independent & Dependent \\
\hline Hero, brave, inspire fear & Nurturing and caring. \\
\hline Problem solver and leader & Follower \\
\hline Competitive and ambitious & Warm and emotional \\
\hline
\end{tabular}

Note: Summarized from: (Eagly \& Wood, 2012 \& England et al., 2011).

This table offers relevant information about the core features that are used to assign roles to men and women and stereotype them. Differences between men and women are usually attributed to the physical characteristics, emotional traits, and personalities of each gender. For instance, society tends to qualify men as stronger than women. Consequently, linguistics and nonlinguistics groups in society can portray stereotypes and develop specific gender roles according to these elements.

It is vital to emphasize that the representation of gender roles and stereotypes transmitted by the media might influence people consciously or unconsciously. Accordingly, these images could have a strong impact on families, children, and society because media is part of our everyday lives and can impact our way of thinking, our perceptions of the world and the things we value (Gauntlett, 2008). Because of gender stereotypes bias, it is more complicated for women to persuade others about their skills as strong leaders and competence at work. Hence, the main purpose of this paper is to evaluate how gender roles and stereotypes are represented in the SNL sketch using some approaches offered by discourse analysis.

\subsection{The transmission of gender roles and stereotypes through mass media}

From the 1970s to the 1990s, some researchers (Busby 1975; Lovdal, 1989; Ferguson et al. 1990) recognize that traditional Western stereotypes of women are transmitted through mass media and advertisements. During these decades, women are mainly represented on TV and other media as sex objects, main consumers of products and decorations as well as the individuals in charge of cleaning and maintaining their houses. In fact, McArthur and Resko (1975) state that women are presented in a relatively unfavorable manner in some selected television commercials bringing unfavorable consequences to individual and social principles. These authors indicate that television is an important area to investigate due to the higher number of hours that the average American spends in front of their TVs. Hence, considering the popularity of the sketch on YouTube and the high number of spectators, the show has broadcast on TV and cable; it is significant to analyze how language is used in the sketch to represent gender stereotypes and gender roles.

\section{Methodology of the study}

This paper investigates how men and women are represented in the sketch GE Big Boys Appliances. To analyze it, I consider some elements of multimodal discourse analysis (MDA). These are: (1) the Systemic Functional Linguistics framework (SFL) by Halliday (1978) to examine the language used, (2) a general overview of critical discourse analysis CDA and (3) the visual semiotic framework developed by Machin (2010). 
This article considers SFL, in a global way, by using a functional model to analyze the context of the situation. It ponders three aspects: (a) the field of the text (what the text is about), (b) the tenor (the relationship between the addresser and the addressee), and (c) the mode (how the text is constructed) (Ewing, 2001: 3). Moreover, the ideational function of SFL is contemplated focusing on transitivity and its processes (material, mental, relational, verbal, behavioral, and existential (Halliday, 2002; Halliday \& Matthissen, 2014). Likewise, CDA serves as a tool to explain relations of power and dominance regarding gender roles and stereotypes. Finally, the visual semiotic framework suggested by Machin (2010) helps us to examine discrepancies and similarities between images and discourse by considering characteristics of the visuals such as gestures, position, activities performed, colors, objects, and contexts. The idea is to present a general view of how gender roles and stereotypes are represented in the sketch by combining some approaches and exploring how they work together to effectively analyze discourse.

\subsection{Multimodal Discourse Analysis (MDA)}

Multimodal Discourse Analysis (MDA) studies how written or spoken discourse combines language and other semiotic features such as images, photographs, diagrams, and graphics to create meaning (Machin, 2010; Machin \& Mayr, 2012). This approach considers that language as well as visual communication influences and is shaped by society. For this article is relevant to take into account how language was used to portray gender roles and stereotypes but also to consider the visual semiotic features of the sketch and the meanings behind the language contemplating some aspects of CDA.

To conduct this analysis, I start by evaluating language using Halliday's (1978) SFL framework. SFL is one of the most significant theories to study language employed in the literature of linguistics and applied linguistics (Abdulrahman, 2016). This theory has its origins in the United Kingdom and later in Australia (O'Donnell 2012: 1) and it is currently used around the world in different fields such as linguistics language education (Christie \& Martin 1997), media discourse (Iedema, 2003), and critical discourse analysis (Bloor \& Bloor, 2007). SFL is both a theory of language and a methodology for analyzing texts and their contexts (Halliday, 1978). It establishes that words mean not only on their own but as an element of a system of meanings. It attempts to comprehend the way language is applied for diverse reasons and in different scenarios as well as it provides useful tools to analyze texts through functions and connections (Halliday, 1985). Through the implementation of SFL, discourse is analyzed contemplating four components: context, semantics, lexico-grammar, and phonology (see Figure 1). However, for this paper, the context of the situation including field, tenor and mode and transitivity are discussed.

Figure 1. The systems and subsystems the context of situation

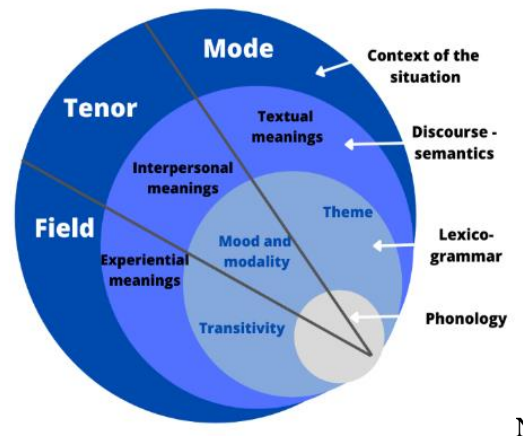

Note: Adapted from: John, 2014. Meaning as choice course, LING 5004. The University of Adelaide [image]. 
As presented in Figure 1, to explore the context of the analysis is central because it represents the circumstances of a setting for an event or idea. Thus, the context influences the general process of making meaning. Context should be analyzed pondering the field, the tenor, and the mode (Halliday, 1978; Halliday \& Matthiessen, 2014). Additionally, as presented in Figure 1, SFL contemplates a model of language with three levels: discourse-semantics (meanings), lexico-grammar (wording), and phonology or graphology (sounds and letters) (Eggins, 2004: 19). The discourse- semantics component consists of three metafunctions. They are interpersonal (related to the interaction between speaker(s) and addressee(s)), ideational (contemplating the grammatical resources for construing our experience of the world around us and inside us), and textual (text) (Halliday \& Matthiessen, 2014). Overall, in this paper, SFL is used to analyze the context of the sketch considering field, tenor, and mode. Likewise, the ideational metafunction of language, specifically transitivity processes. These processes are evaluated to explore the way language assists to accomplish specific ideologies pondering the roles and stereotypes represented in the skit.

\subsection{Critical Discourse Analysis (CDA)}

Deivis and Elder (2004) explain that CDA "concerns itself with issues of identity, dominance and resistance, and with seeking out evidence in text - especially (to date) media and advertising texts, and political documents and speeches - of class, gender, ethnic and other kinds of bias" (p. 140). In this sense, CDA investigates linguistic characters, cultural processes, and structures to evaluate how power relations are exercised and negotiated in discourse. In this order of ideas, Hart (2010) establishes that CDA addresses social problems, power relations, ideological work and social actions considering society, culture, and history. Likewise, Van Dijk (2001) describes CDA as the study of implicit and indirect meaning in texts. In other words, it aims to investigate the opaque and transparent meanings related to underlying beliefs, views, and perceptions of social inequalities and issues as they are expressed in spoken and written discourse. For this analysis, CDA is used to examine some of the utterances examining the text itself but also the context and the relationship of the characters to determine how gender roles and stereotypes are represented.

\subsection{Visual Semiotic Analysis (VSA)}

The visual semiotic features that are analyzed in this paper represent some scenes that are shown in the sketch. To evaluate them, Machin's framework (2010) provides a collection of resources to systematically evaluate images and pictures as well as the meaning they intend to communicate through visual semiotic resources. Machin (2010: 36) emphasizes that "a designer may use a particular feature or element to connote a particular discourse which communicates about kinds of persons, attitudes, values and actions". Therefore, to understand meaning represented in discourse, it is convenient to consider the additional elements presented such as visuals.

The author proposes an iconographic analysis of visuals which involves paying attention to objects, persons, settings, and poses as a way to convey and communicate meaning (Machin, 2010). The author suggests a kit of strategies that allow analysts to evaluate visuals in a systematic and organized way. This framework suggests analysts to consider the following features to evaluate visuals: (1) iconographical elements such as poses, gaze, social distance, objects and settings; (2) modality (details of elements and background, light and shadow, tone, depth of vision, modulation of colors, and saturation of colors); (3) dimensions of colors (brightness, saturation, purity, modulation, luminosity, and hue). Some of these features are considered in 
this paper to explore visual semiotic resources and their potential to mean and realize in specific contexts.

\section{Analysis and discussion of the sketch}

The sketch to be analyzed is GE Big Boys Appliances aired from New York in 2018. The skit is available on YouTube ${ }^{1}$ and has more than five and a half million views this year. This fake commercial is analyzed considering an MDA approach. The spoken discourse presented in the skit is examined considering the SFL model suggested by Halliday (1978) and CDA as a standpoint. Moreover, the visual and gestures presented in the sketch are evaluated pondering the semiotic analysis proposed by Machin (2010).

\subsection{Description of the sketch}

For this language analysis the SFL framework promoted by Halliday (1978) is deemed. In this case, I contemplate the functional model to analyze the situational context. Therefore, field, tenor and mode are appraised.

Table 3. Features of the context (field and tenor)

\begin{tabular}{|l|l|}
\hline \multicolumn{2}{|l|}{ Features of the context } \\
\hline Field & $\begin{array}{l}\text { A man advertises some products that are designed for doing housework } \\
\text { and using them transforms house duties into a men's job. The man shows } \\
\text { and uses different appliances that are designed for strong and tall men. }\end{array}$ \\
\hline Tenor & $\begin{array}{l}\text { Inside: A man describing GE big boys appliances. } \\
\text { Outside: Jason Momoa and the SNL audience (18-49 years old). }\end{array}$ \\
\hline
\end{tabular}

The field describes the overall situation of the skit: a man's doing housework by using appliances for strong men. The tenor indicates the relationship between the characters. In the inside, Jason Momoa explains the main characteristics of the products. On the other hand, outside the sketch the relationship is between the actor and the audience of the show. As observed, the aim of the sketch is persuading other people (the audience) to by the fake appliances by highlighting the features of the products. As well, the sketch emphasizes the requirements that the products' users should have to utilize them. For instance, they need to be strong and tall.

After considering the field and the tenor of the context, it is significant to explore the mode and the mood chosen for the skit. Table 4 illustrates the choices between indicative (declarative or interrogative) and imperative clauses.

Table 4. Features of the context (Mode)

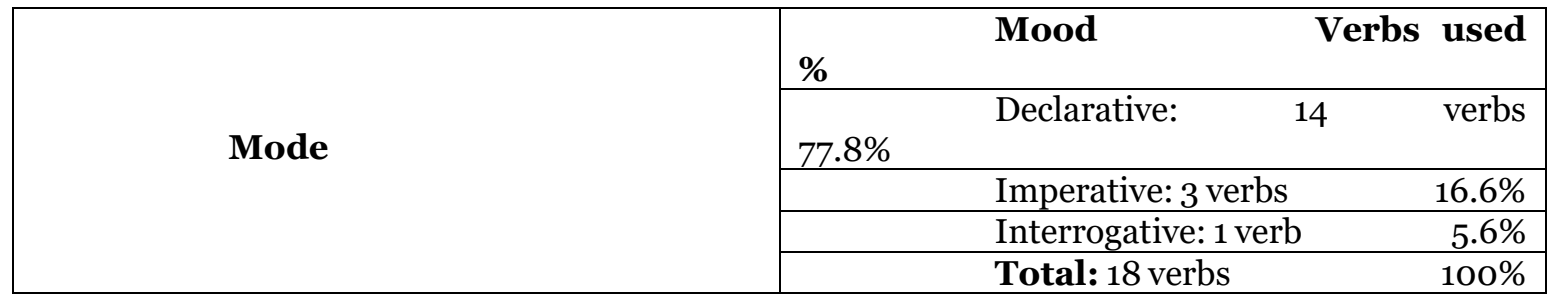

\footnotetext{
${ }^{1}$ https://www.youtube.com/watch?v=vZRzJJcq6Rs.
} 
K. Clemente-Escobar - GE Big Boys Appliances: Towards a Multimodal Discourse...

Regarding the mode, $77.8 \%$ of the verbs are in the declarative form, $16.6 \%$ imperative and only $5.6 \%$ interrogative. It means that there is lack of interaction between characters in the sketch because it aims to emphasize the features of the appliances to "advertise" the products.

Table 5. Transitivity analysis

\begin{tabular}{|c|c|c|c|c|}
\hline $\begin{array}{c}\text { Process } \\
\text { Type }\end{array}$ & $\begin{array}{l}\text { Category } \\
\text { meaning }\end{array}$ & Verbs found & Frequency & Percentage \\
\hline Material & $\begin{array}{l}\text { Doing or } \\
\text { happening }\end{array}$ & $\begin{array}{l}\text { Give, get, climb, } \\
\text { use, buy, } \\
\text { annihilate, run } \\
\text { on, keep, stand, } \\
\text { have }\end{array}$ & 12 & $48 \%$ \\
\hline \multirow[t]{3}{*}{ Mental } & Sensing & see & 2 & \multirow{3}{*}{$20 \%$} \\
\hline & feeling & like & 2 & \\
\hline & thinking & mean & 1 & \\
\hline \multirow[t]{2}{*}{ Relational } & Attributing & To be & 2 & \multirow[b]{2}{*}{$12 \%$} \\
\hline & Identifying & To be & 1 & \\
\hline Verbal & Saying & Ask, tell & 3 & $12 \%$ \\
\hline Behavioral & Behaving & Ride on & 2 & $8 \%$ \\
\hline Existential & & & 0 & \\
\hline
\end{tabular}

As shown in Table 5, material processes account for $48 \%$ of the total number of processes in the text. These processes represent a good choice to demonstrate the useful qualities of the appliances described in the sketch because they relate to doing, happening or action. The process with the second highest percentage is the mental process and it relates to the cognitive reaction to a certain event or circumstance. The less frequent processes are the verbal and behavioral ones $12 \%$ and $8 \%$ respectively. The existential process did not occur in the discourse employed in the text.

Another aspect that should be mentioned regarding language is the repetitive use of the adjective big and the noun boy (6 times) to emphasize that men are physically stronger than women. Additionally, in the discourse the man included the word sucker to reflect that men are not delicate, on the contrary, they are brave and as men they could use informal language to show their strength (social stereotype). Likewise, the language used is informal considering the implementation of phrasal verbs (man up, run on, ride on, etc.) as well as the contracted forms (I'd, she'd, don't) are presented.

\subsection{Critical discourse analysis of the utterances of the fake commercial}

In this section, I analyze the discourse presented in a fake commercial for GE Big Boys Appliances from a CDA stance. In the next table, I introduce some utterances expressed by the man in the skit and the critical analysis of them.

Table 6. Critical discourse analysis of the utterances

\begin{tabular}{|l|l|}
\hline \multicolumn{1}{|c|}{ Utterances } & \multicolumn{1}{|c|}{ Critical Analysis } \\
\hline $\begin{array}{l}\text { 1. These days women are the primary breadwinners of } \\
\text { 50\% of American homes and that means housework is a } \\
\text { man's job. }\end{array}$ & $\begin{array}{l}\text { Traditionally, gender stereotypes state that men are the main } \\
\text { breadwinners at home. This utterance highlights that the } \\
\text { situation is changing and now women oversee providing food } \\
\text { and economic support to their homes. However, even though } \\
59 \% \text { of women work outside home does not mean that they earn } \\
\text { all the money required to fulfill all the family needs. So, this is } \\
\text { an exaggeration. }\end{array}$ \\
\hline
\end{tabular}




\begin{tabular}{|l|l|}
$\begin{array}{l}\text { 2. Give them the tools to get the job done right with GE } \\
\text { big boy home appliances }\end{array}$ & $\begin{array}{l}\text { This suggests that if men are required to do housework, they } \\
\text { need appliances that are big, heavy, and tall because they } \\
\text { represent the strong sex. In other words, men are expected to } \\
\text { be strong while women are supposed to be delicate and weak. }\end{array}$ \\
\begin{tabular}{l|l} 
3. Big boy dishwasher, featuring a 70-pound steel door. \\
I'd like to see a woman do that
\end{tabular} & $\begin{array}{l}\text { The man expresses that a woman is not capable of lifting a 70- } \\
\text { pound dishwasher highlighting that women are weak and } \\
\text { delicate. Consequently, they cannot do hard work. }\end{array}$ \\
$\begin{array}{l}\text { 4. She may have climbed the corporate ladder, but she'll } \\
\text { need an actual ladder to use the big boy washing machine }\end{array}$ & $\begin{array}{l}\text { This means that women can get new job opportunities and } \\
\text { higher positions in diverse professional areas. However, they } \\
\text { are not tall enough to use this washing machine. }\end{array}$ \\
\hline $\begin{array}{l}\text { 5. All GE Big Boy appliances have an energy star rating } \\
\text { of half minus because they run on gas }\end{array}$ & $\begin{array}{l}\text { The man indicates that men are so tough that they do not need } \\
\text { appliances which work with electricity that is why these } \\
\text { appliances need gas to function. }\end{array}$ \\
\hline $\begin{array}{l}\text { 6. Man up this holiday season and ask your wife to buy } \\
\text { you GE Big Boy household appliances. }\end{array}$ & $\begin{array}{l}\text { This means that men's bravery consists of asking their wives to } \\
\text { buy these appliances for them. Thus, the man establishes that } \\
\text { times have changed completely, and women should spoil their } \\
\text { men by buying them the equipment or appliances they need or } \\
\text { want. }\end{array}$ \\
\hline
\end{tabular}

Through the sketch, it is observed that the man's role has changed. The skit shows that the man is in charge of taking care of the kids, cleaning and organizing the house, and preparing food. However, the products advertised are designed for men who are physically strong and tall. Therefore, the video emphasizes that gender roles have changed but gender stereotypes remain the same.

\subsection{Machin's framework: Visual semiotic analysis of the comedy sketch}

In this part of the paper, I describe the visuals shown in the fake advertisement. I will pay attention to the gestures, position, and activities performed by the characters as well as the colors, objects, and contexts of the images. I start with the photography of women in the sketch.

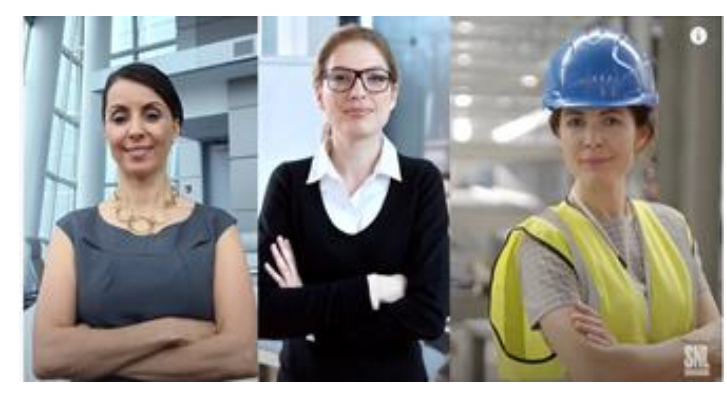

Image 1. Women. Source: SNL. GE Big Boy Appliances, 2018.

This photograph shows the image of successful women who got access to management positions in their jobs. The picture tries to represent how women can have jobs in fields they were not accepted in the past. They stand in a row and in their background, they have the buildings of their companies. So, it seems that they are leaders in the prestigious and modern companies where they work. The first woman looks like a businesswoman, the second one is like an executive and the third one seems to be an engineer in a factory. It is supposed that they should be confident, empowered, proud and happy because they were able to get to higher positions at work. However, if we pay attention to their posture, they are looking directly at the viewers, but their arms are crossed. In terms of body language, crossed arms express that the people are defensive and that is a feature of discomfort and insecurity. Consequently, even though women are presented as 
managers of important companies, they do not seem to be confident with their positions. Likewise, women are smiling in the pictures, but they do not seem genuinely happy.

The second picture to be evaluated is a representation of men's and women's roles. The features considered in the previous picture are analyzed with this one too.

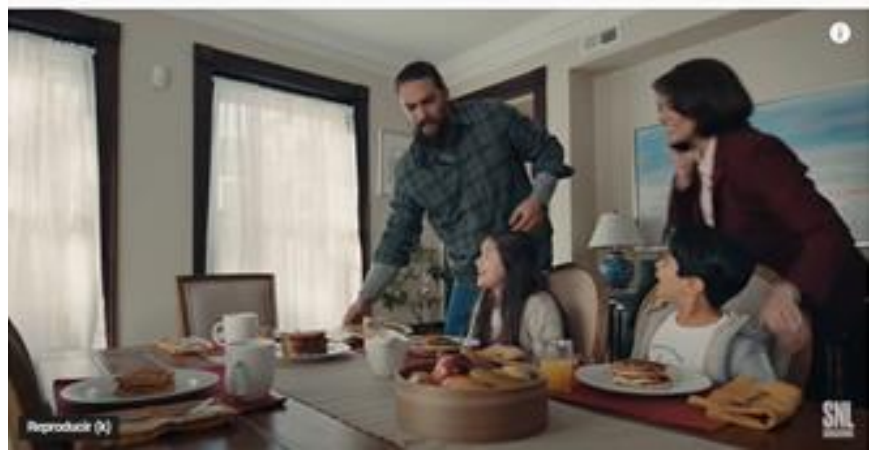

Image 2. Men's and women's roles. Source: SNL. GE Big Boy Appliances, 2018.

The family is together having breakfast in a clean, modern, comfortable, and middleclass home. The house has big windows, a large dining room, modern and attractive furniture, and nice tableware. Additionally, the breakfast consists of pancakes, orange juice and coffee. Thus, it seems that this is the home of a medium class family. The woman seems to be busy answering a call. She is wearing an executive outfit. On the contrary, the man is wearing jeans and he is serving breakfast to the children. Everybody looks happy. The picture has bright colors and good lighting. The children are happy, they are eating a common American breakfast and getting ready for their daily routine.

The third picture to be evaluated is a representation of the house and the slogan $\mathrm{A}$ man's job.

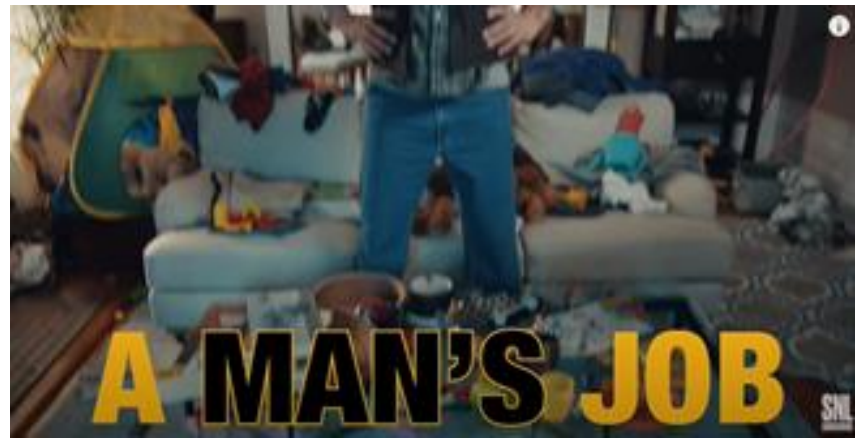

Image 3. A man's job. Source: SNL. GE Big Boy Appliances, 2018.

In this image, in the background, the house is dirty and disorganized. The man is standing up with his hands on his hips. This means that he is ready to start cleaning and organizing the house because that is his job as a man. Likewise, the man is adopting the superman/superhero posture or a high-power pose with broad stance, hands on hips, shoulders high and pushed back. Carney et al. (2010) claims that a high-power pose produce elevations in testosterone, decreases in cortisol, and increase feelings of power and tolerance for risk. Therefore, practicing this posture could help people to feel empower and confident about the job they do. From this, we can infer that the actor shows the audience that the task he will do is demanding and difficult, but as a superhero, he will do it better than expected because he is pure testosterone.

The fourth picture shows the characteristics of one of the appliances: The dishwasher. 


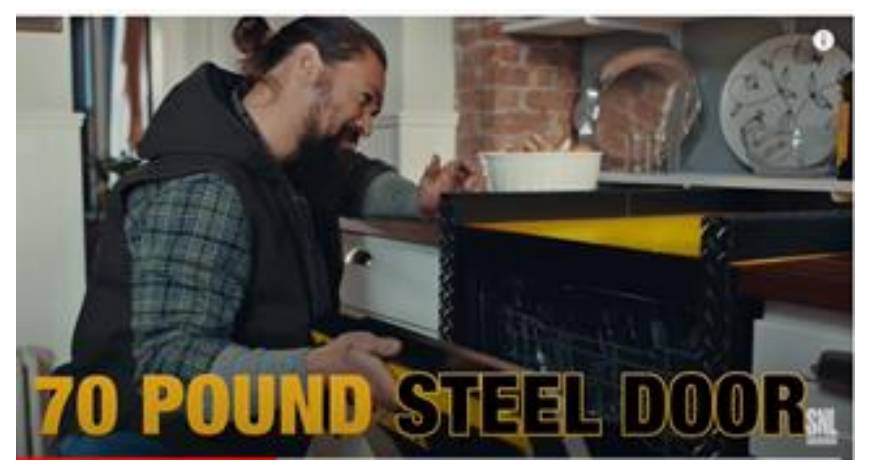

Image 4. The dishwasher. Source: SNL. GE Big Boy Appliances, 2018.

The dishwasher is heavy and to make it attractive for men, it is black and yellow, big and heavy. The dishwasher is 70 pounds and its door is made of pure steel. This picture highlights the effort the man is making to close the dishwasher door. His face shows that he makes a great effort to close the machine. When he finishes, he said: I want to see a woman doing that. This means that now the women are out of the house, with these appliances' women are not able to do housework. housework.

The fifth image shows how the men have fun and drink while they are doing

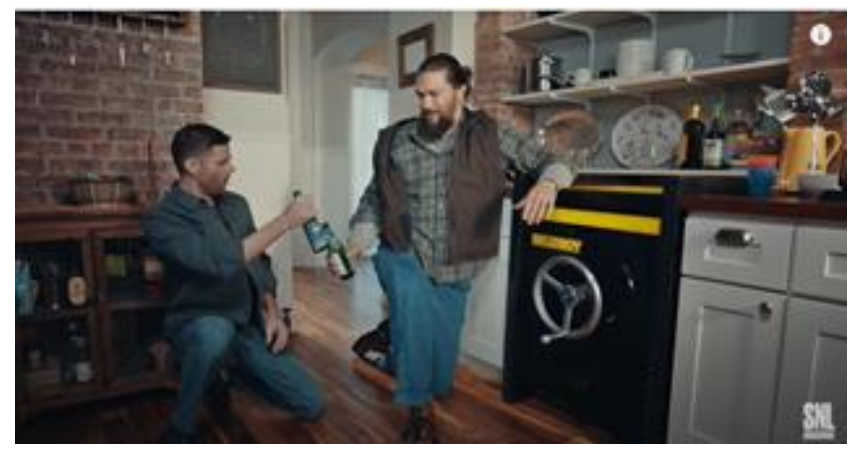

Image 5. It is an easy job. Source: SNL. GE Big Boy Appliances, 2018.

This image represents that despite the fact the man has to lift a lot of weight and made a great effort to use the appliances and get the job done, he has the energy and the time to grab a beer and spend time with his friend. In the image, he does not look tired. On the contrary, he seems to be happy and energetic. They are making a toast. Maybe, celebrating that they finish they household activities. According to this picture, doing household chores with these big appliances is easy for him. There is not a job that men are not able to do. Consequently, they represent the strong gender.

\section{Conclusion}

This MDA intended to explore the sketch GE Big Boys Appliances aired by the comedy show SNL in 2008. The analysis was offered with three main approaches. Halliday's SFL (1978), Machin's (2010) visual framework and CDA. The combination of frameworks allowed me to offer a critical analysis to understand how gender roles and stereotypes are represented. In the last few decades, the role of women in social life has changed and a high percentage of women have assumed challenging roles in society. As represented in the sketch, gender roles have changed because women work full time, are providers at home and they have become business leaders, innovators, and entrepreneurs in different fields. However, the discourse in the sketch reports that 
K. Clemente-Escobar - GE Big Boys Appliances: Towards a Multimodal Discourse...

classical stereotypes are still transmitted. Men are perceived as physically stronger and taller as well as problem solvers and leaders in what they do. Thus, considering the high number of views of SNL show and the millions of people who have watched the video on YouTube, it is interesting to see how classical stereotypes are transmitted despite the recent changes in gender roles.

The discourse that mass media and social media uses represent a device that can benefit or damage society because the way gender is represented in comedy shows does have an influence on how we perceive gender roles and stereotypes and how men and women behave in relation to each other. Therefore, the findings of this paper invite readers to be more critical when watching comedy sketches and programs offered on mass and social media, especially for educational purposes. In the local context, this work represents initial efforts to combine different approaches to analyze comedy sketches. For further research, I recommend conducting a deeper analysis considering the three metafunctions of language ideational, textual, and intrapersonal and all the semiotic features recommended in Machin's framework.

\section{Acknowledgements}

This research did not receive any specific grant from funding agencies in the public commercial, or not-for-profit sectors.

The author declares no competing interests.

\section{References}

Bloor, T., \& Bloor, M. (2007). The functional analysis of English (2nd ed.). London: Edward Arnold.

Britvec, R. (2020). The importance of humor: Laughter is the best medicine. Explore Life. https://www.explore-life.com/en/articles/the-importance-of-humor.

Bucholtz, M. (2003). Theories of discourse as theories of gender: Discourse analysis in language and gender studies. In J. Holmes \& M. Meyerhoff (Eds.), The Handbook of Language and Gender (pp. 4368). Blackwell Publishing Ltd. https://doi.org/10.1002/9780470756942

Busby, L. J. (1975). Sex role research on the mass media. Journal of Communication, 25(Autumn), 107-131.

Carney, D. R., Cuddy, A. J. C., \& Yap, A. J. (2010). Power posing: Brief nonverbal displays affect neuroendocrine levels and risk tolerance. Psychological science, 21(10), 1363-1368. https://www.doi.org/10.1177/0956797610383437

Changxue, X. (2008). Critically evaluate the understanding of gender as discourse. International Educational Studies Journal, 1(2), 54-57.

Christie, F., \& Martin, J. (1997). Genre and institutions: Social processes in the workplace and school. London \& New York: Continuum.

Deivis, A., \& Elder, C. (2004). The handbook of applied linguistics. Oxford: Blackwell Publishing.

Eagly, A. H., Wood, W., \& Diekman, A. B. (2000). Social role theory of sex differences and similarities: A current appraisal. In T. Eckes \& H. M. Trautner (Eds.), The developmental social psychology of gender (pp. 123-174). Lawrence Erlbaum Associates Publishers.

Eggins, S. (2004). Introduction to systemic functional linguistics. London: A\&C Black.

England, D. E., Descartes, L., \& Collier-Meek, M. A. (2011). Gender role portrayal and the Disney princesses. Sex Roles, 64(7-8), 555-567. https://www.doi.org/10.1007/s11199-011-9930-7 
Ferguson, J. H., Kreshal, P. J., \& Tinkham, S. F. (1990). In the pages of Ms.: Sex role portrayals of women in advertising. Journal of Advertising, 19(1), 40-51.

Gauntlett, David (2008). Media, gender and Identity An introduction, 2nd edition. London: Routledge.

Halliday, M. A. K. (1978). Language as social semiotic: The social interpretation of language and meaning. Edward Arnold.

Halliday, M. A. K. (1985). An introduction to functional grammar. Arnold.

Halliday, M. A. K. (2002). Linguistic studies of text and discourse. In J. Webster (Ed.), The collected works of M. A. K. Halliday (Vol. 2, Issue 2). Continuum.

Halliday, M. A. K., \& Matthiessen, C. M. I. M. (2014). Halliday's introduction to functional grammar (4 ${ }^{\text {th }}$ ed.). New York: Routledge.

Hart, C. (2010). Critical discourse analysis and cognitive science: New perspectives on immigration discourse. Palgrave.

History (2020, April 15). Saturday Night Live debut. A\&E Television Networks. https://www.history.com/this-day-in-history/saturday-night-live-debuts.

Iedema, R. (2003). Discourses of post-bureaucratic organization ( $1^{\text {st }}$ ed.). Amsterdam: John Benjamins Pub.

Inge, M. T. (2005). The study of humor in America and its founders. Studies in American Humor, 13(1), 12. www.jstor.org/stable/42573475.

Juschka, D. (2016). Feminism and gender theory. The Oxford Handbook of the Study of Religion, 1(1), 1-15. https://doi.org/10.1093/oxfordhb/9780198729570.013.10

John, J. (2014). Meaning as choice course. LING 5004. The University of Adelaide.

Le Page, R., \& Tabouret-Keller, A. (1985). Acts of identity: Creole-based approaches to language and ethnicity. Cambridge University Press.

Lovdal, L. T. (1989). Sex role messages in television commercials: An update. Sex Roles, 21(11/12), 715-724.

Martin, R. A. (2007). The psychology of humor: An integrative approach. Elsevier Academic Press.

Marx, N., Sienkiewicz, M., \& Becker, R. (2013). Saturday Night Live and American TV. Indiana University Press.

McArthur, L., \& Resko, B. (1975). The portrayal of men and women in American television commercials. Journal of Social Psychology, 97(2), 209-220. https://doi.org/10.1080/00224545.1975.9923340

Meyer, J. C. (2000). Humor as a double-edged sword: Four functions of humor in communication. http://citeseerx.ist.psu.edu/viewdoc/download?doi=10.1.1.466.1116\&rep=rep1\&type=pdf.

O’Donnell, M. (2012). Introduction to systemic functional linguistics for discourse analysis. Language, Function and Cognition, pp. 1-8.

Ramos, D. (2021). January 28, 202. "Saturday Night Live" Season 46 Ranked No. 1 Among All Comedies On Broadcast And Cable. Deadline. https://deadline.com/2021/01/saturday-night-live-nbc-snltv-ratings-1234682808/.

Veenstra, G. (2011). Race, gender, class, and sexual orientation: intersecting axes of inequality and self-rated health in Canada. Int J Equity Health, 1O(3), 1-11. https://doi.org/10.1186/1475-9276-10-3 
K. Clemente-Escobar - GE Big Boys Appliances: Towards a Multimodal Discourse...

C O A $\mathbf{s}$ 